\title{
Effect of Needle Punching Process on a Chopped Strand Mat Composite with an Open Hole
}

\author{
Daiki Ichikawa1, Hiroyuki Hamada ${ }^{2}$, Akio Ohtani ${ }^{3}$ \\ ${ }^{1}$ Graduate School of Kyoto Institute of Technology, Kyoto, Japan \\ ${ }^{2}$ Future-Applied Conventional Technology Center, Kyoto Institute of Technology, Kyoto, Japan \\ ${ }^{3}$ Faculty of Fiber Science and Engineering, Kyoto Institute of Technology, Kyoto, Japan \\ Email: i.athena.d5.mcg@gmail.com
}

How to cite this paper: Ichikawa, D., Hamada, H. and Ohtani, A. (2018) Effect of Needle Punching Process on a Chopped Strand Mat Composite with an Open Hole. Open Journal of Composite Materials, 8, 110-123.

https://doi.org/10.4236/ojcm.2018.83009

Received: May 13, 2018

Accepted: July 16, 2018

Published: July 19, 2018

Copyright (C) 2018 by authors and Scientific Research Publishing Inc. This work is licensed under the Creative Commons Attribution International License (CC BY 4.0).

http://creativecommons.org/licenses/by/4.0/

\begin{abstract}
The easiest and most reliable joining method is the mechanical joint with a bolt and nut or rivet. However, in the case of composite laminates, mechanical joint properties decrease because of lower interlaminar properties compared to in-plane properties around hole. This study investigated needle punching process with the aim of improving the mechanical properties in the thickness direction of fiber-reinforced plastic composite laminates with an open hole. Needle punching process was applied to glass fiber chopped strand matused as the reinforcement for the composite laminates. Open-hole tensile tests and observations of end cross-sections after the tests were performed. The tensile properties and fracture mechanism of the specimens subjected to needle punching process were investigated. In addition, characteristic distance (a parameter for evaluating resistance to fracture in open-hole tensile test specimens) was also calculated to examine the effects of needle punching process conditions on fracture toughness. Tensile strength was improved by more than $15 \%$ by needle punching process. However, when a certain needle punching density was exceeded, the mechanical properties worsened. In addition, characteristic distance increased with increasing needle punching density. Thus, these results suggest that there is an optimal needle punching density with respect to strength and characteristic distance.
\end{abstract}

\section{Keywords}

Fiber-Reinforced Plastic, Needle Punch, Chopped Strand Mat, Open Hole, Characteristic Distance

\section{Introduction}

In recent years, fiber reinforced plastic (FRP) composites, which offer high spe- 
cific strength and high specific rigidity, have been used in a wide variety of fields, ranging from large passenger aircraft such as the Boeing 787 to vehicles and sports equipment. When composites are used in various applications such as these, they need to be joined with other members, the same as in the case of metal materials. Joints of metal materials are made by welding or by creating holes and using mechanical joints such as bolts or rivets. However, in the case of composite materials, the strength of joints made using welding or adhesives is not especially high, and there are problems with long-term durability and product management if adhesives are used [1] [2] [3]. Because of this, mechanical joints are said to have relatively high reliability for composite materials. However, there are items of concern even for mechanical joints of composite materials. When stress concentrates around mechanical joints in composite laminates, local fracture can occur together with delamination, and the load bearing capacity of the entire structure suddenly decreases [4]. Because of this, improvement of interlaminar characteristics is necessary in order to improve the mechanical characteristics of mechanical joints in composite laminates. Although various studies have investigated ways to improve the interlaminar characteristics of composite laminates [5] [6] [7] [8] [9], here we focused on applying needle punching process to the reinforcement of the composite material as means of improving these characteristics. Needle punching process is a fabric processing method that is used to create non-woven fabric and is able to create interlacing of fabrics in the thickness direction by piercing cottony fiber with special barbed needles called felting needles. When this technique is used to strengthen composite materials, it is thought to improve the interlaminar characteristics of stacked layer materials by causing fibers to be oriented in the thickness direction, and to suppress delamination due to stress concentration around holes. Previous research applying the needle punching technique to the reinforcement of composite materials has been conducted, for example, applying needle punching process to glass fiber chopped strand mat $(\mathrm{CM})$ and testing the tensile properties of composite reinforced using this reinforcement [10]. Another study has investigated the mechanical properties of composite using non-woven fabrics and woven fabrics made from glass fiber with application of needle punching process [11]. However, no study has examined the effects of holes on the mechanical properties of composites using a reinforcement subjected to needle punching process.

In this study, we fabricated a composite material using a reinforcement in which needle punching process was applied to CM. We then investigated the effects of needle punching process conditions on the tensile properties and fracture propagation behavior of specimens with holes. In addition, evaluations were performed using characteristic distance to investigate the effect of changing needle punching process conditions on the ease of fracture when a hole is present in the specimen. Proposed by Nuismer et al. [12] [13], characteristic distance is an important parameter for evaluating the ease of failure of tensile test specimens with holes. This research investigated the effect of needle punching 
process conditions on characteristic distance.

\section{Methods}

\subsection{Fabrication of Reinforcement}

A needle punching glass chopped strand mat (NCM) was used in this research. It is a reinforcement formed by applying needle punching process using felting needles to CM (weight: $450 \mathrm{~g} / \mathrm{m}^{2}$ : MC $450 \mathrm{~A}$, Nitto Boseki Co., Ltd.). Figure 1 shows pictures and schematics of the felting needles used to fabricate NCM, and Table 1 shows the details of each needle. This research used three types of felting needles (labeled A, B, and C) (Groz-Beckert KG) with different needle thicknesses and shapes of barbs attached to the needle surface. Felting needle $\mathrm{A}$ is a \#25 needle (needle thickness: $0.85 \mathrm{~mm}$ ) with a kick-up, felting needle $\mathrm{B}$ is a \#32 needle (needle thickness: $0.68 \mathrm{~mm}$ ) with a kick-up, and felting needle $\mathrm{C}$ is a $\# 25$ needle without a kick-up. The kick-up is a part that protrudes outside the thickness of the needle as shown in Figure 1. During needle punching process, fibers are hooked by the barbs and become oriented in the thickness direction. When a kick-up is present, the amount of fibers hooked by the needle is expected to increase.

NCM was fabricated by installing needle punching plates fitted with each of the three different types of felting needles into a non-woven fabric manufacturing device (Needle room NH-380:Daiwa-kiko Co., Ltd.). NCM was needle punch processed by feeding two layers of CM simultaneously into the non-woven fabric

Table 1. Details of the felting needles.

\begin{tabular}{cccc}
\hline Needle & Barbs shape & Kick-up & Thickness of the needle (mm) \\
\hline A & (1) & $\bigcirc$ & 0.85 \\
B & $(1)$ & $\bigcirc$ & 0.68 \\
C & (2) & $\times$ & 0.85 \\
\hline
\end{tabular}

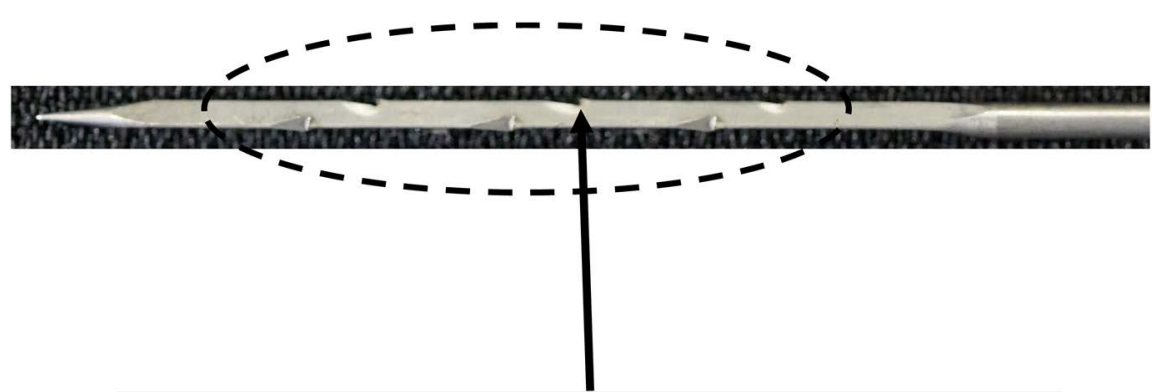

Side of needle

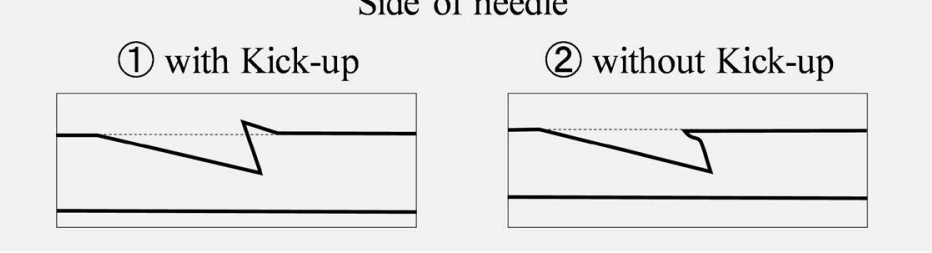

Figure 1. Schematic of felting needle. 
manufacturing device along the longitudinal direction of the CM base material rolls. The needle depth was set to $15 \mathrm{~mm}$ and the reinforcement feed rate was set to $7,9,12,15$, and 17 ( $\mathrm{mm} /$ count). The needle depth is the depth to which the felting needles penetrate the reinforcement with each punch, and the feed rate is the length by which the reinforcement is fed after each punch. The density per unit area of needle punching process is calculated from Equation (1) using the reinforcement feed rate [14].

$$
N=m \cdot \frac{n_{0}}{L}
$$

here, $N$ [holes $\left./ \mathrm{cm}^{2}\right]$ is the needle punching density, $L[\mathrm{~mm} /$ count $]$ is the feeding speed, $m[\mathrm{~m}]$ is the length of the metal plate with felting needles, and $n_{0}\left[\mathrm{G} / \mathrm{m}^{2}\right]$ is the number of needles per unit area. In this research, we fabricated NCM with different needle punching density by changing the reinforcement feeding speed in five steps while retaining the same fabrication conditions used in previous research [15]. Furthermore, since there are many types of NCM in this study, the reinforcement name is defined as the combination of the needle type $(A, B, C)$ and the needle punching density $\left(12.3,13.9,17.4,23.2,29.9\right.$ holes $\left./ \mathrm{cm}^{2}\right)$. For example, A-12.3 is the reinforcement fabricated using felting needle A at a needle punching density of 12.3 holes $/ \mathrm{cm}^{2}$.

\subsection{Specimen Preparation and Testing Method}

The specimens used in this study were formed by using the hand layup method using unsaturated polystyrene resin (RIGOLAC: 150HR BQNTNA, SHOWA DENKO Co., Ltd.) as the matrix resin. After forming, a weight was placed on top and a pressure of $9 \mathrm{kPa}$ was applied. Furthermore, a spacer was used so that the thickness of each specimen was around $1.5 \mathrm{~mm}$. The fiber volume fraction was around $20 \%$. After the resin was cured at room temperature for $24 \mathrm{~h}$, post curing was performed for $2 \mathrm{~h}$ in a $100^{\circ} \mathrm{C}$ thermostatic bath to complete the curing. After forming, the specimens were cut into strips using a compact universal cutting machine (MC-120, Maruto Instrument Co., Ltd.). Figure 2 shows the dimensions of the specimens. A hole of diameter $10 \mathrm{~mm}$ was drilled in the center of the specimens with drill press and an ultra-hard drill for FRP (HAM-342, HAM Japan Co., Ltd.).

\subsection{Test Method}

The open hole tensile test was performed using a universal tester (Type 5949, Instron Co., Ltd.). The test conditions were test speed of $1 \mathrm{~mm} / \mathrm{min}$ and spacing between grips of $100 \mathrm{~mm}$. The tensile strengths of the specimens with a hole were found by using Equation (2).

$$
\sigma=\frac{P}{(W-D) T}
$$

here, $\sigma[\mathrm{MPa}]$ is the tensile strength with a hole, $P[\mathrm{~N}]$ is the maximum load, $W$ $[\mathrm{mm}]$ is the specimen width, $D[\mathrm{~mm}]$ is the hole diameter, and $T[\mathrm{~mm}]$ is the 


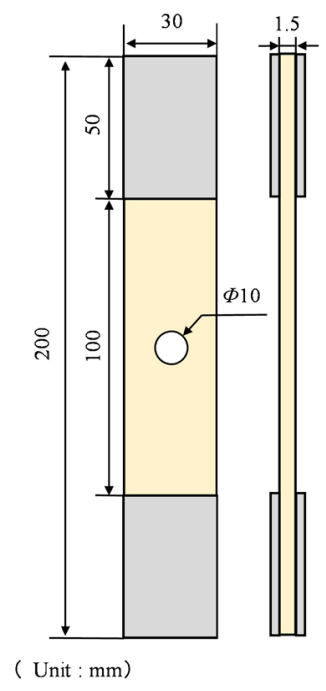

Figure 2. Schematic of specimens.

specimen thickness. Furthermore, video was captured using a digital single-lens reflex camera ( $\alpha 5100$, SonyCo., Ltd.) to observe the fracture propagation behavior during the open hole tensile test.

After the open hole tensile test, the end cross-sections of the specimens were observed in order to investigate the fracture mechanism. Cross-sectional polishing to a mirror finish was performed using a table-top sample polisher (IM-P2, IMTCo., Ltd.) with waterproof abrasive paper and alumina powder. The cross-sections were observed using an inverted metallurgical microscope (GX41, OlympusCo., Ltd.).

\subsection{Evaluation by Characteristic Distance}

Evaluation by characteristic distance is based on the point stress criterion proposed by Whitney et al. for assessing the strength of open hole tensile test specimens [16]. This criterion is explained in Figure 3. According to this criterion, ultimate failure of a specimen with an open hole occurs when the region with tensile stress $\left(\sigma_{\mathrm{y}}\right)$ exceeding the tensile strength of the material $\left(\sigma_{0}\right)$ in the minimum cross-section of the specimen progresses a distance $\left(\mathrm{R}_{\mathrm{OT}}\right)$ from the hole edge under a tensile load. This distance $\mathrm{R}_{\mathrm{OT}}$ is called the characteristic distance. Thus, fracture occurs when the stress value along $\mathrm{R}_{\mathrm{OT}}$ reaches the tensile strength of the material. In other words, a material with a hole is more resistant to fracture when the characteristic distance is longer. In this study, stress around the hole at fracture was found by finite-element method (FEM) stress analysis (Marc Student Edition 2016.0.0, MSC Software Co., Ltd.), and the characteristic distance $\mathrm{R}_{\mathrm{OT}}$ was found by applying point stress criterion theory to the obtained stress distribution. Specifically, the characteristic distance $\mathrm{R}_{\text {От }}$ was calculated by finding the distance from the hole edge to the location where the tensile stress $\left(\sigma_{\mathrm{y}}\right)$ distribution in the minimum cross-section at the fracture load $\left(\mathrm{P}_{\mathrm{NT}}\right)$ on the openhole tensile test specimen was equal to the tensile strength of the material 
$\left(\sigma_{0}\right) . \mathrm{P}_{\mathrm{NT}}$ and $\sigma_{0}$ were actually measured, and the $\sigma_{\mathrm{y}}$ distribution was found by FEM stress analysis as described above. Figure 4 shows the FEM model that was used. This model was 2-dimensional and composed by plane strain element, and converted into a half-model by making use of the symmetry. Linear analysis was performed assuming plane strain conditions by applying forced displacement. Table 2 shows the material constants that were used. The longitudinal elastic modulus $(E)$ was calculated from tensile tests of flat smooth material without any holes, and Poisson's ratio $(v)$ was fixed at 0.3 . Furthermore, the modulus of rigidity $(G)$ was calculated using Equation (3).

$$
G=\frac{E}{2(1+v)}
$$

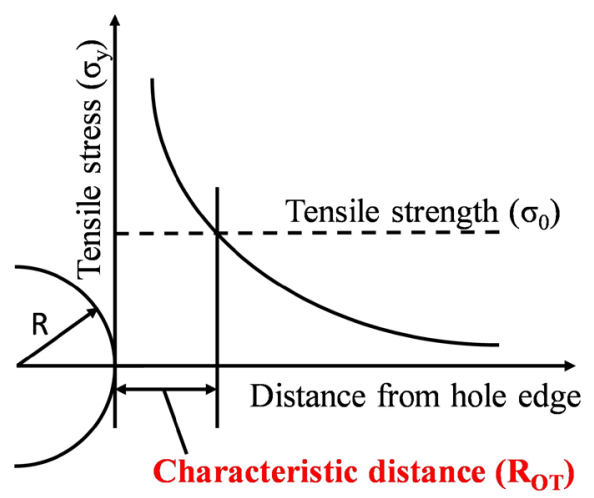

Figure 3. Description of the point stress criterion.

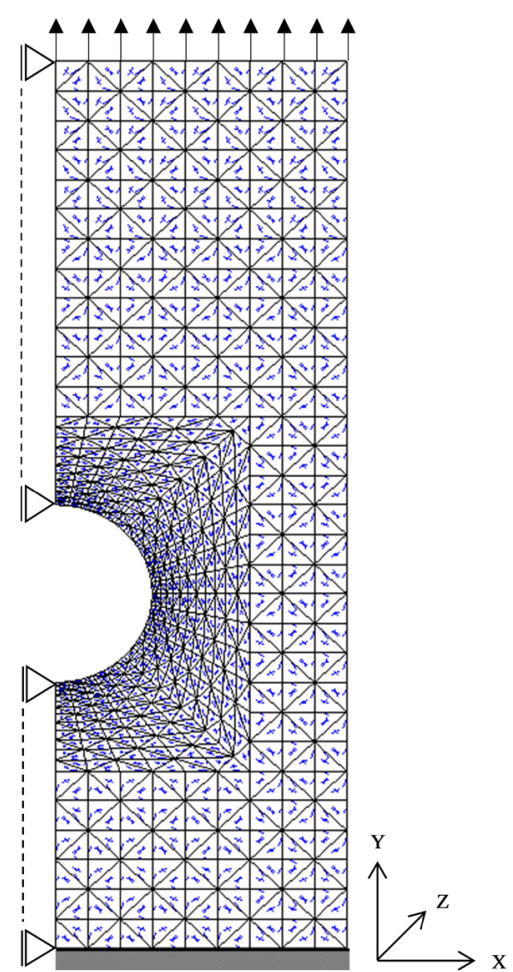

Figure 4. Example of mesh division for FEM. 
Table 2. Parameters used for FEM.

\begin{tabular}{cccc}
\hline Density $\left(\right.$ holes $\left./ \mathrm{cm}^{2}\right)$ & $\begin{array}{c}\mathrm{E} \\
(\mathrm{GPa})\end{array}$ & $\begin{array}{c}\mathrm{G} \\
(\mathrm{GPa})\end{array}$ & $v$ \\
\hline 0 & 9.7 & 3.7 & 0.3 \\
12.3 & 8.9 & 3.4 & 0.3 \\
13.9 & 9.1 & 3.5 & 0.3 \\
17.4 & 10.0 & 3.8 & 0.3 \\
23.2 & 10.0 & 3.9 & 0.3 \\
29.9 & 9.3 & 3.6 & 0.3 \\
\hline
\end{tabular}

The contact point at the lower edge of the specimen was fixed, and the contact point at the upper edge of the specimen was forcibly displaced until reaching $\mathrm{P}_{\mathrm{NT}} / 2$ overall.

\section{Results and Discussion}

\subsection{Open Hole Tensile Test}

Figures 5-7 show representative stress-strain curves of specimens that had been subjected to needle punching process using felting needles $\mathrm{A}, \mathrm{B}$, and $\mathrm{C}$, respectively. These stress-strain curves show that fracture strain was increased by needle punching process with all of the felting needles. Furthermore, the stress at fracture was often observed to be higher than that of CM.

Figure 8 shows the relationship between tensile strength and needle punching density for each specimen of the NCM composites. The material with needle punching density 0 holes $/ \mathrm{cm}^{2}$ is the CM composite. The NCM composites exhibited essentially the same trend regardless of the type of felting needle, with the strength initially increasing with increasing needle punching density and then decreasing at a needle punching density of 17.4 holes $/ \mathrm{cm}^{2}$ or higher. Comparison of A and B, which differed in terms of only needle thickness, revealed that $\mathrm{A}$ had higher strength at the same density. Furthermore, comparison of A and C, which differed in terms of only the presence or absence of the kick-up, revealed that the curve for $\mathrm{C}$ rises more gently and then decreases more gently than the curve for A. It was found that, in comparison with the CM composite, felting needle A increased tensile strength by a maximum of approximately $15 \%$, felting needle $\mathrm{B}$ by approximately $7 \%$, and felting needle $\mathrm{C}$ also by approximately $7 \%$. Furthermore, in the NCM composites fabricated using felting needle A, there is clear improvement in their tensile properties [15]. Compared to the previous research results, it was found that the NCM composites fabricated in this study had similar increases in tensile strength due to needle punching process, and the trends differed according to needle punching density. From the above, it is clear that a thicker needle with a kick-up produces a larger increase in tensile strength. 


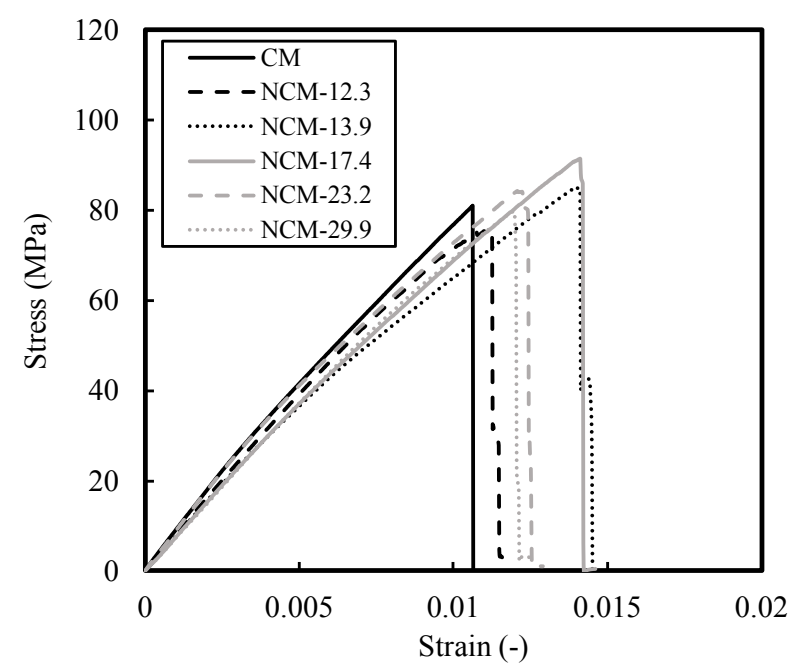

Figure 5. Stress-strain curves (felt needle A).

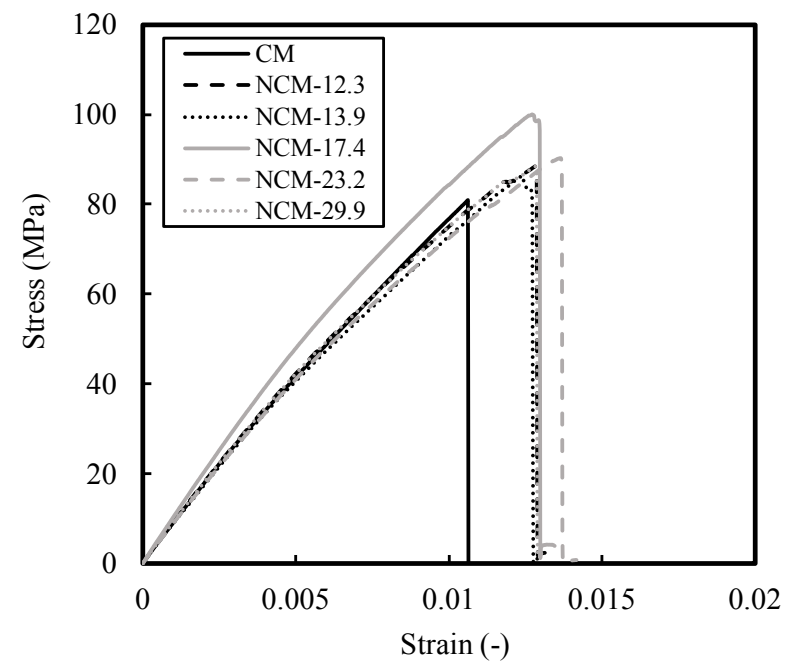

Figure 6. Stress-strain curves (felt needle B).

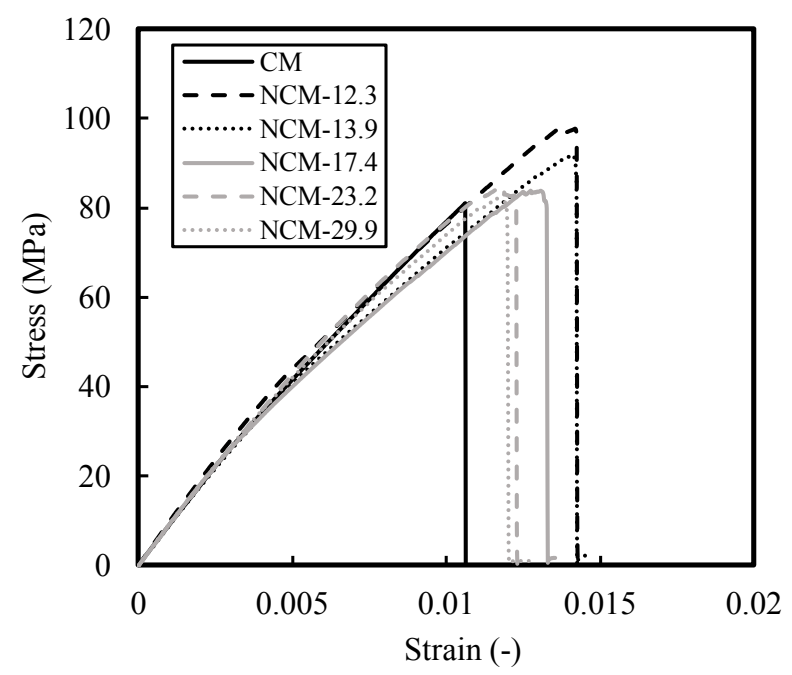

Figure 7. Stress-strain curves (felt needle C). 


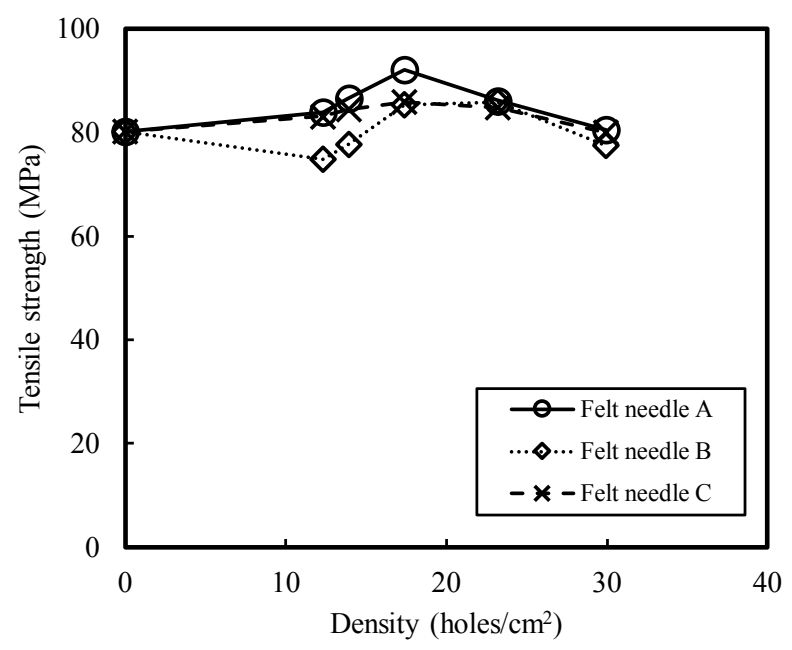

Figure 8. Relationship between tensile strength and needle punching density.

Although these results show that the different types of felting needles had some effect on the tensile properties, because no large differences were found in the observed trends, subsequent studies were performed using only the NCM composite fabricated using felting needle $\mathrm{A}$, which exhibited the highest tensile strength.

Next, differences in fracture propagation behavior were investigated by using video of the area around the hole recorded during tensile tests. Figure 9 shows photos of the external appearance of the CM composite and the NCM-17.4 and NCM-29.9 specimens that were fabricated using felting needle A as representative examples during fracture propagation and after break off. For both the CM and NCM composites, cracking initiated and progressed from the edge of the hole as the load was increased. However, after this, the fracture mechanism observed in the CM composite involved cracking in a fan shape, whereas the cracking was relatively straight in the NCM composites. The same fracture propagation behavior was observed in NCM composites even when the needle punching density was different. These observed trends in fracture propagation behavior were consistent with those observed in previous research [15].

Next, end cross-sections of the specimens were observed. Figure 10 shows a schematic diagram of the cross-sectional observation area, and Figure 11 shows cross-sectional photos and schematic diagrams of the CM, NCM-17.4, and NCM-29.9 specimens. For the CM composite, a fracture mechanism was observed that involved a small number of transverse cracks and delamination.

The number of transverse cracks in the end cross-section of the specimen after each test and the length of delamination were quantified from the cross-sectional observation results in Figure 11. Figure 12 shows the relationship between the number of transverse cracks and needle punching density, and Figure 13 shows the relationship between delamination length and needle punching density. These results show that the number of transverse cracks increases and the delamination length decreases with increasing needle punching 
density.

In light of the above results, we next investigated differences in fracture propagation behavior depending on whether or not needle punching process was performed. Figure 14 shows schematic diagrams of fracture progression in the $\mathrm{CM}$ composite. In the $\mathrm{CM}$ specimen, a crack at the edge of the hole propagated perpendicular to the load direction. As this cracking propagated, transverse crack occurred and propagated in the thickness direction around the tip of the fissure, and delamination is thought to have occurred when this crack tip reached interface between the layers. As the crack propagates from the edge of the hole, the area where transverse cracks and delamination occur grows accompanying delamination due to the transverse cracks. Then, fan-shaped cracks form at ultimate failure. In contrast, it is thought that the number of transverse cracks was larger in the NCM composites than in CM composite because the number of points from which transverse cracks initiated increased due to the dispersion of fiber bundles as the number of fiber bundles oriented in the thickness direction increased. However, the fiber bundles oriented in the thickness direction suppressed the occurrence of delamination, and therefore fracture propagation followed a relatively straight path.

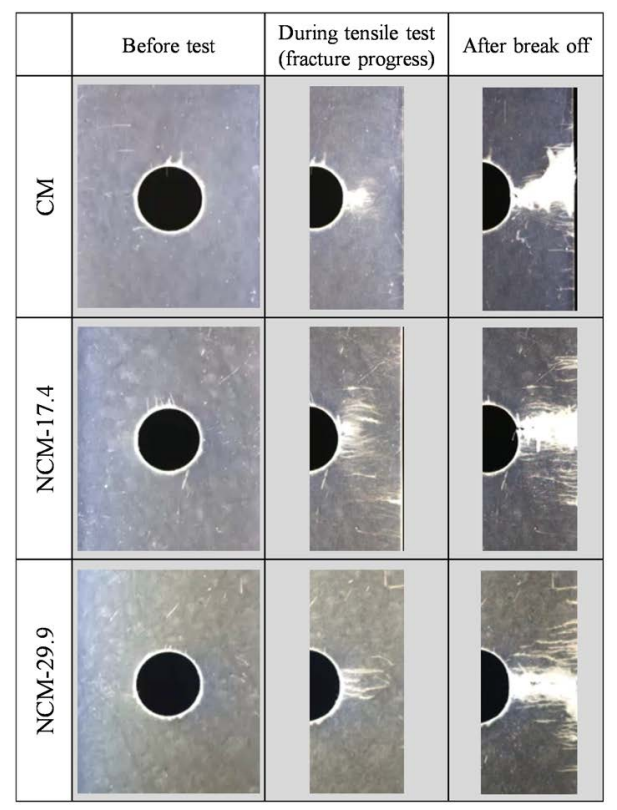

Figure 9. Differences in fracture propagation behavior around the hole for the CM, NCM-17.4, and NCM-29.9 specimens.

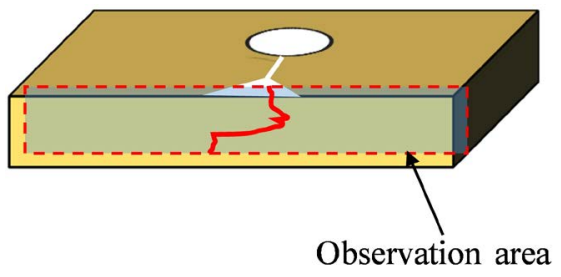

Figure 10. Schematic of the observation area of end cross-sections. 


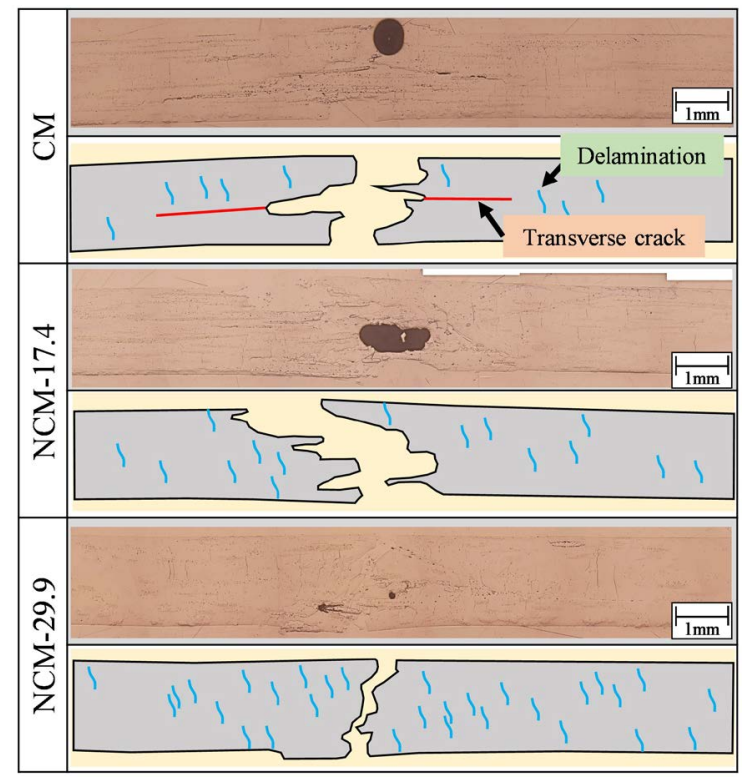

Figure 11. Cross-sectional observation of the fracture surface of the CM, NCM-17.4, and NCM-17.4 specimens with an open hole.

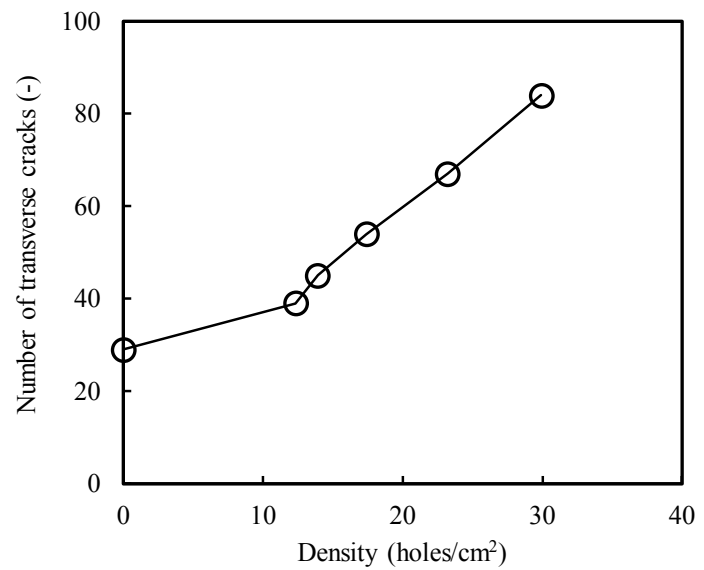

Figure 12. Relationship between number of transverse cracks and needle punching density.

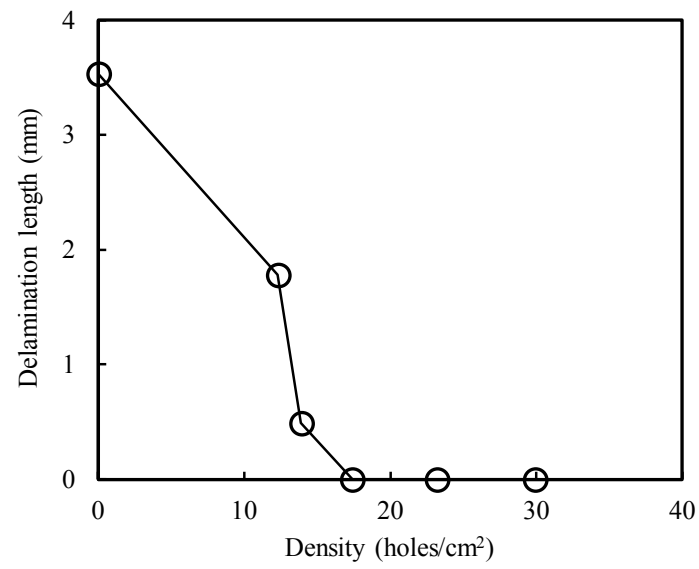

Figure 13. Relationship between delamination length and needle punching density. 


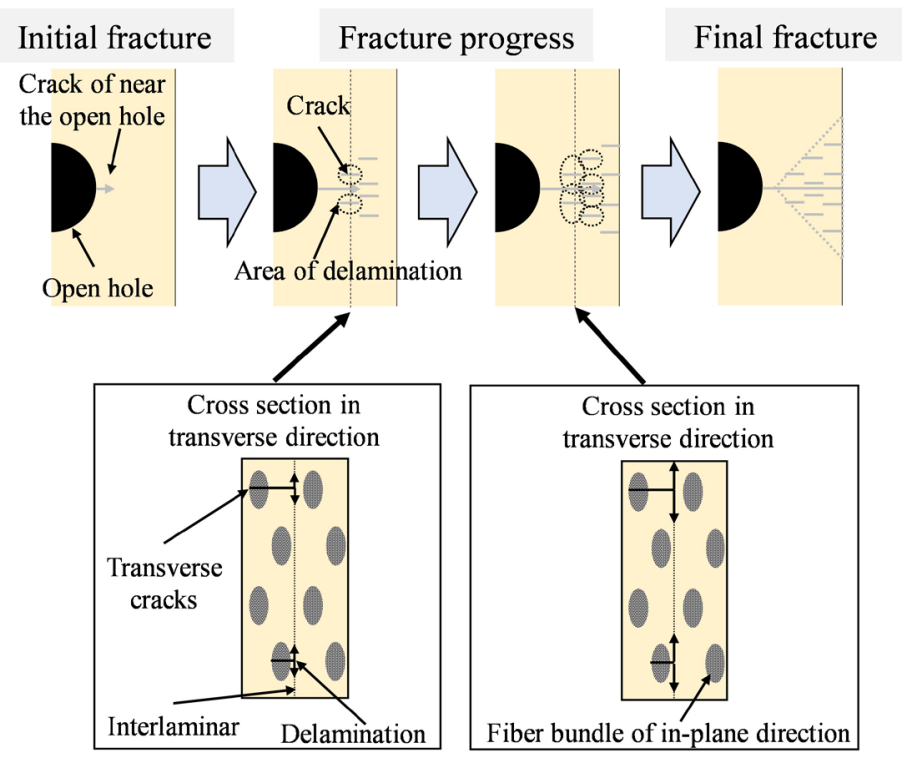

Figure 14. Changes in fracture propagation around the hole for a CM specimen.

Next, we discuss the reason for the variation in mechanical properties depending on the needle punching density as shown in Figure 8. Increasing strength with increasing needle punching density may be attributable to the effect of the larger dispersion of fibers. Previous research has found that the dispersion of fibers was promoted by needle punching process [17] [18]. Therefore, the tensile properties are thought to have been improved by the elimination of resin-rich areas and the reduction of variation in the stress distribution as a result of the increasing dispersion of fibers by needle punching process. However, the amount of fibers oriented in the in-plane direction decreased and the reinforcing fibers became shorter with increasing needle punching density, and the number of transverse cracks increased as the dispersion of fibers and the number of fiber bundles in the thickness direction increased. Thus, it is thought that the mechanical properties worsened when the needle punching density was increased too greatly.

\subsection{Characteristic Distance under Tensile Load}

Figure 15 shows the relationship between the open hole tensile strength and characteristic distance $\left(\mathrm{R}_{\mathrm{OT}}\right)$ in NCM composites fabricated using felting needle A. The plotted black circles show results for the CM composite. At a needle punching density of $12.3 \mathrm{holes} / \mathrm{cm}^{2}$, the strength was essentially unchanged and $\mathrm{R}_{\mathrm{OT}}$ was shorter than that of the CM specimen. After this, the strength and $\mathrm{R}_{\mathrm{OT}}$ increased with increasing needle punching density, and at a needle punching density of $23.2 \mathrm{holes} / \mathrm{cm}^{2}$, both the strength and characteristic distance exceeded those of the CM specimens. As the needle punching density was then further increased, $\mathrm{R}_{\mathrm{OT}}$ increased but strength decreased. These results show that needle punching process increased not only strength but also $\mathrm{R}_{\mathrm{OT}}$. This is attributed to 


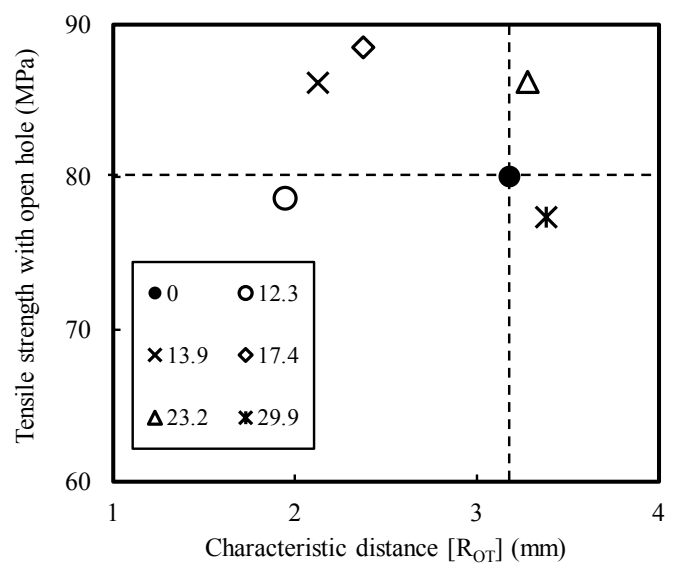

Figure 15. Relationship between tensile strength and characteristic distance.

the rapid propagation of delamination being suppressed by fiber bundles oriented in the thickness direction as a result of needle punching process, as shown in Figure 14. These results show that there is an optimal needle punching density not only for strength, but also for resistance to failure when a hole is present.

\section{Conclusions}

This study investigated the effect of needle punching process conditions on the tensile properties and fracture propagation behavior of composite laminates with a hole. In addition, we investigated the characteristic distance, which is an important parameter for evaluating the resistance of open hole tensile test specimens to failure.

It was found that the tensile strength of composite materials with a hole could be increased by increasing the dispersion of fibers and reducing variations in the stress distribution by applying needle punching process to a CM composite. However, because the amount of fibers oriented in the in-plane direction decreased and the reinforcing fibers became shorter with increasing needle punching density, and the number of transverse cracks increased with increasing dispersion of fibers and an increasing number of fiber bundles in the thickness direction, the mechanical properties decreased when the needle punching density was increased too greatly.

Evaluation using the characteristic distance showed that there is an optimal needle punching density not only in terms of strength, but also in terms of resistance to fracture when a hole is present in composites subjected to needle punching process.

\section{References}

[1] Yamaguchi, Y. (1996) Joining Fiber Reinforced Plastics. Journal of the Japan Welding Society, 65, 463-468. https://doi.org/10.2207/qjjws1943.65.6_463

[2] Fukuda, H., Ben, G. and Suemasu, H. (2011) Compendium of Composite Materials and Technology. New Edition, 404-417.

[3] Sato, C. (2014) Adhesive Bonding for FRP. Journal of the Adhesion Society of Ja- 
pan, 50, 175-178. https://doi.org/10.11618/adhesion.50.175

[4] Hatta, H., Kougo, Y., Asano, T. and Sawada, Y. (1997) Pin Joint Strength of C/C Composites. Transactions of the Japan Society of Mechanical Engineers Series A, 63, 1586-1593. https://doi.org/10.1299/kikaia.63.1586

[5] Nojima, T. and Kusaka, T. (1997) Fracture Behaviors of CFRP Laminates in Mode I Interlaminar Fracture Toughness Testing. Transactions of the Japan Society of $\mathrm{Me}$ chanical Engineers Series A, 63, 879-885. https://doi.org/10.1299/kikaia.63.879

[6] Iwahori, Y. and Ishikawa, T. (2014) Impact Damage to Laminar Reinforced Composite Materials. The Proceeding of the Materials and Processing Conference, Hiroshima, 13 November 2014, 185-186.

[7] Yamauchi, Y., Kurokawa, T. and Kusaka, T. (1993) Estimation of Dynamic Interlaminar Fracture Toughness of CFRP by ENF Test Using SHPB Method. Journal of the Society of Materials Science, 42, 1445-1451. https://doi.org/10.2472/jsms.42.1445

[8] Arai, M., Hirokawa, J., Hanamura, Y., Ito, H., Hojo, M. and Quaresimin, M. (2014) Characteristic of Mode I Fatigue Crack Propagation of CFRP Laminates Toughened with CNF Interlayer. Composites Part B, 65, 26-33. https://doi.org/10.1016/j.compositesb.2014.02.025

[9] Kusaka, T., Kurokawa, T. and Yamauchi, Y. (1994) Strain Rate Dependence of Mode II Interlaminar Fracture Toughness of Unidirectional CF/Epoxy Composite Laminates. Journal of the Society of Materials Science, 43, 445-450. https://doi.org/10.2472/jsms.43.445

[10] Zhang, Z., Hazemoto, M., Yang, Y. and Hamada, H. (2013) Fracture Analysis of Needle Punched Nonwoven Composite with Open Holes. Proceedings of the 19th International Conference on Composite Materials (ICCM), Montreal, 28 July-2 August 2013, 8458-8466.

[11] Lee, S. and Kang, T. (2000) Mechanical and Impact Properties of Needle Punched Nonwoven Composites. Journal of Composite Materials, 34, 816-840. https://doi.org/10.1177/002199830003401001

[12] Nuismer, R. and Labor, J. (1978) Applications of the Average Stress Failure Criterion: Part I-Tension. Journal of Composite Materials, 12, 238-249. https://doi.org/10.1177/002199837801200302

[13] Nuismer, R. and Labor, J. (1978) Applications of the Average Stress Failure Criterion: Part II-Compression. Journal of Composite Materials, 13, 49-60. https://doi.org/10.1177/002199837901300104

[14] Miura, Y. (1985) Non-Woven Fabrics. Kobunshikankokai, Kyoto, 56-57.

[15] Ichikawa, D., Marui, R., Morii, T. and Ohtani, A. (2015) Static and Dynamic Properties of Needle Punched Chopped Strand Mats Composite with Open Hole. Proceedings of the 20 th International Conference on Composite Materials (ICCM-20), Copenhagen, 19-24 July 2015, 1-10.

[16] Whitney, J. and Nuismer, R. (1974) Stress Fracture Criteria for Laminated Composites Containing Stress Concentrations. Journal of Composite Materials, 8, 253-265. https://doi.org/10.1177/002199837400800303

[17] Ichikawa, D., Marui, R., Morii, T. and Ohtani, A. (2017) Effect of Needle Punching Process on Fatigue and Residual Properties of Chopped Strand Mat Composites. Proceedings of the 2017 International Conference on Materials \& Processing (ICMP2017), Los Angeles, 4 June 2017, 1-7.

[18] Ichikawa, D., Morii, T., Hamada, H. and Ohtani, A. (2018) Effect on Residual Strength Properties of Needle Punched Chopped Strand Mat Composites. Mechanical Engineering Journal, 5, 1-9. https://doi.org/10.1299/mej.17-00445 